\title{
RESEARCH
}

Open Access

\section{Prognostic factors in patients with metastatic spine tumors derived from lung cancer-a novel scoring system for predicting life expectancy}

Hiroshi Uei and Yasuaki Tokuhashi* ${ }^{*}$

\begin{abstract}
Background: Recently, molecule-targeting and bone-modifying agents have improved the treatment outcomes of lung cancer-derived metastatic spine tumors. Therefore, the prognostic factors for such tumors were examined, and novel scoring systems for predicting the life expectancy of patients with such tumors were proposed.

Methods: In 207 patients with lung cancer-derived metastatic spine tumors (surgery 49; conservative therapy 158), we retrospectively examined the factors that influenced the post-treatment survival time (age, sex, the affected site, pathology, general condition, the number of extraspinal bone metastases, the number of spinal metastases, the presence/absence of major internal organ metastasis, paralysis state, the total Tokuhashi score, the serum alkaline phosphatase level, the serum carcinoembryonic antigen level, molecule-targeting drug treatment, and bonemodifying agent treatment). Based on the results, we devised novel scoring systems for predicting the prognosis of such patients.
\end{abstract}

Results: Univariate analyses showed that the pathology of the primary lung tumor, the patient's general condition and paralysis state, and the presence/absence of molecule-targeting drug treatment significantly influenced survival. We performed a Cox regression analysis of these four factors and developed criteria for a novel scoring system based on the patient's general condition and paralysis state, which exhibited significance in the regression analysis. A retrospective review indicated that the consistency rate between predicted life expectancy and actual survival was $67.3 \%$. When criteria based on the four factors that exhibited significance in the univariate analyses were adopted, the consistency rate was $76.2 \%$.

Conclusion: The patient's general condition and paralysis state, the pathology of the primary lung tumor, and molecule-targeting drug treatment influenced survival among patients with lung cancer-derived metastatic spine tumors. Novel scoring systems based on these four factors were proposed.

Keywords: Metastatic spine tumor, Lung cancer, Molecule-targeting drug, Prognostic evaluation system, Scoring system, Treatment modality

\footnotetext{
* Correspondence: tokuhashi.yasuaki@nihon-u.ac.jp

Department of Orthopaedic Surgery, Nihon University School of Medicine,

30-1 Oyaguchi-kamicho, Itabashi-ku, Tokyo 173-8610, Japan
}

(c) The Author(s). 2018 Open Access This article is distributed under the terms of the Creative Commons Attribution 4.0 International License (http://creativecommons.org/licenses/by/4.0/), which permits unrestricted use, distribution, and reproduction in any medium, provided you give appropriate credit to the original author(s) and the source, provide a link to the Creative Commons license, and indicate if changes were made. The Creative Commons Public Domain Dedication waiver (http://creativecommons.org/publicdomain/zero/1.0/) applies to the data made available in this article, unless otherwise stated. 


\section{Background}

Bone metastasis from lung cancer is detected in approximately 30 to $40 \%$ of patients with advanced non-small cell lung cancer, who exhibit a median survival time of $<1$ year. A retrospective study involving patients with non-small cell lung cancer in Japan showed that the incidence of bone metastasis during the follow-up period was $30.4 \%$. The most frequent site of bone metastasis was the spine [1].

Metastatic spine tumors derived from lung cancer exhibit rapid progression, leading to an unfavorable prognosis. In fact, they are the most difficult to treat of all metastatic spine tumors [2]. In many patients, paralysis progresses rapidly, and the most appropriate treatment must be determined promptly [2-6]. Recently, moleculetargeting and bone-modifying agents (BMA) have improved the treatment outcomes of lung cancer and lung cancer-derived spinal metastasis [7-11].

Since 1990, the optimal treatment for metastatic spine tumors has been selected based on prognostic predictions obtained using a revised version of the Tokuhashi score (Table 1) $[12,13]$. In lung cancer patients, the maximum total Tokuhashi score is 10 points, and it is difficult to predict a life expectancy of $\geq 1$ year using the present criteria. We used to use the Tokuhashi scoring system, which we developed, to determine the optimal treatment strategy for lung cancer patients with metastatic spine tumors. The ability of this system to predict the prognosis of patients with spinal metastasis has been examined in many previous studies around the world [14-19]. However, recently, as patients with lung cancer-derived metastatic spine tumors have started to survive longer, greater discrepancies have been seen between life expectancy predictions obtained using the Tokuhashi score and actual post-treatment survival times. Therefore, a new prognostic evaluation system is required for determining the optimal treatment options for such patients, including whether spinal surgery should be performed. In this study, we examined the prognostic factors for lung cancer-derived metastatic spine tumors and proposed novel scoring systems for predicting the prognoses of patients with such tumors.

\section{Methods}

\section{Subjects}

The subjects were 207 patients with lung cancer-derived metastatic spine tumors (surgery 49; conservative therapy 158) who visited our department after 2000.

The inclusion criteria were as follows: the patient had a lung cancer-derived metastatic spine tumor and was symptomatic; the patient complained of back pain and pain and/ or paralysis of the extremities; the treatment was selected in collaboration with oncologists and radiotherapists based on an evaluation of the pathology of the lung cancer, its
Table 1 A revised Tokuhashi score [13]

\begin{tabular}{|c|c|}
\hline Predictive factor & Score (points) \\
\hline \multicolumn{2}{|l|}{ General condition } \\
\hline Poor (KPS 10-40\%) & 0 \\
\hline Moderate (KPS 50-70\%) & 1 \\
\hline Good (KPS 80-100\%) & 2 \\
\hline \multicolumn{2}{|l|}{ Number of extraspinal bone metastases foci } \\
\hline$\geq 3$ & 0 \\
\hline $1-2$ & 1 \\
\hline 0 & 2 \\
\hline \multicolumn{2}{|l|}{ Number of metastases in the vertebral body } \\
\hline$\geq 3$ & 0 \\
\hline 2 & 1 \\
\hline 1 & 2 \\
\hline \multicolumn{2}{|l|}{ Metastases to the major internal organs } \\
\hline Unremovable & 0 \\
\hline Removable & 1 \\
\hline No metastases & 2 \\
\hline \multicolumn{2}{|l|}{ Primary site of the cancer } \\
\hline $\begin{array}{l}\text { Lung, osteosarcoma, stomach, } \\
\text { bladder, esophagus, pancreas }\end{array}$ & 0 \\
\hline Liver, gallbladder, unidentified & 1 \\
\hline Others & 2 \\
\hline Kidney, uterus & 3 \\
\hline Rectum & 4 \\
\hline Thyroid, prostate, breast, carcinoid tumor & 5 \\
\hline \multicolumn{2}{|l|}{ Spinal cord palsy } \\
\hline Complete (Frankel A, B) & 0 \\
\hline Incomplete (Frankel C, D) & 1 \\
\hline None (Frankel E) & 2 \\
\hline Total points & Predicted prognosis \\
\hline $0-8$ & $<6$ months \\
\hline $9-11$ & $\geq 6$ months \\
\hline $12-15$ & $\geq 1$ year \\
\hline
\end{tabular}

KPS indicates Karnofsky's performance status

sensitivity to adjuvant treatment, and the patient's general condition and expected survival time; the decision-making process and any treatments were administered promptly and could be adjusted appropriately in urgent cases; and the date of the patient's death was known.

The exclusion criteria were as follows: (1) patients who were administered the main constituent of the initial treatment for the spinal metastasis at another institution, (2) patients who dropped out of the follow-up process, and (3) patients whose date of death could not be confirmed.

The surgical indications were as follows: (1) pain and/or paralysis caused by spinal instability, (2) pain and/or paralysis due to spinal cord invasion by the tumor, and (3) 
long-term local control in patients with localized lesions and a life expectancy of at least 1 year. The surgical procedures consisted of posterior stabilization with decompression in 27 patients, posterior stabilization without decompression in 10 patients, posterior decompression alone in 2 patients, anterior stabilization with decompression in 8 patients, anteroposterior stabilization with decompression in 1 patient, and total en bloc spondylectomy in 1 patient. Of the 158 patients who underwent conservative therapy, symptomatic therapy alone was administered to 37 patients. Adjuvant therapy was administered to the remaining 121 patients and most of the patients that underwent surgery. Finally, chemotherapy (excluding molecule-targeting drugs), radiotherapy, molecule-targeting drugs, and BMA were administered to 96, 102, 59, and 143 patients, respectively. Cisplatin and carboplatin were usually used for the chemotherapy. In the radiotherapy, 20-30 Gy (in 2 to 3 Gy fractions) radiation were administered. The administered molecule-targeting drugs included gefitinib, erlotinib, bevacizumab, axitinib, crizotinib, and afatinib. In principle, $250 \mathrm{mg}$ oral gefitinib were administered daily for adenocarcinoma if a mutation was detected in the epidermal growth factor receptor gene. If the gefitinib became insufficient, $150 \mathrm{mg}$ erlotinib or $40 \mathrm{mg}$ oral afatinib were administered daily. $500 \mathrm{mg}$ oral crizotinib were administered daily for adenocarcinoma when the ALK gene was detected.

The administered BMA included zoledronic acid, a bisphosphonate, and denosumab, an anti-receptor activator of nuclear factor kappa-B ligand (RANKL) antibody. $4 \mathrm{mg} / \mathrm{month}$ intravenous zoledronate or $120 \mathrm{mg} /$ month subcutaneous denosumab were administered where possible. In principle, the BMA were administered as soon as spinal metastasis was detected.

Based on the patients' status and wishes, multiple treatment methods were employed where possible.

\section{Methods}

This was a retrospective and mono-institutional study. We examined the factors that influenced the post-treatment survival time, including age, sex, the affected site, the pathology of the primary lung tumor, the patient's general condition, the number of extraspinal bone metastases, the number of spinal metastases, the presence/absence of main organ metastasis (especially the liver metastasis), the patient's paralysis state, the total Tokuhashi score, the alkaline phosphatase (ALP) level, the carcinoembryonic antigen (CEA) level, the presence/absence of moleculetargeting drug treatment, and the presence/absence of BMA treatment. The post-treatment survival time was defined as the period from the start of treatment for spinal metastasis until death. In other words, the post-treatment survival time included the treatment period.
Based on these results, we devised novel scoring systems for predicting the prognosis of patients with lung cancer-derived metastatic spine tumors by combining the factors that had a significant influence on patient prognosis.

The study protocol was approved by the institutional ethics committee of Nihon University Itabashi Hospital (approval number RK-11209-8).

\section{Statistical analysis}

To investigate the factors that influenced the post-treatment survival time, univariate analyses were performed using the $t$ test, Welch's method, or analysis of variance (ANOVA). A multivariate analysis involving the factors that exhibited significance in the univariate analyses was conducted using Cox's regression analysis. We used the StatMate $\mathrm{V}^{\circ}$ software (Atoms Co., Tokyo, Japan) for all statistical analyses.

\section{Results \\ Post-treatment survival time}

The mean post-treatment survival time of the $207 \mathrm{pa}$ tients with lung cancer-derived metastatic spine tumors was $8.26 \pm 12.15$ months (range $0.2-114$ months).

\section{Univariate analyses of the factors that influenced the post-treatment survival time \\ Sex}

The subjects consisted of 136 males and 71 females, who exhibited mean survival times of $7.1 \pm 8.7$ and 10.8 \pm 16.6 months, respectively $(p=0.0803)$.

\section{Age}

The mean survival times of the subjects aged $\leq 69$ years $(n=117)$ and $\geq 70$ years $(n=90)$ were $8.9 \pm 14.0$ and 7.8 \pm 9.2 months, respectively $(p=0.8002)$.

\section{The affected site (symptom level)}

Cervical, thoracic, and lumbosacral lesions were seen in 27,119 , and 61 patients, respectively. In these 3 groups, the mean survival time was $5.9 \pm 7.3,10.3 \pm 15.8$, and 5.9 \pm 7.3 months, respectively ( $p=0.1603)$.

\section{Pathology of the primary lung cancer}

We investigated the cases of 177 patients in whom a definitive pathological diagnosis was finally made $(120,24$, 24, and 9 patients were diagnosed with adenocarcinoma, small cell carcinoma, squamous cell carcinoma, and others, respectively). The mean survival times of the adenocarcinoma and non-adenocarcinoma patients were $10.0 \pm 14.0$ and $6.4 \pm 7.6$ months, respectively $(p=0.0263)$. 


\section{Tokuhashi score parameters}

We also examined the prognostic significance of the factors included in each category of the Tokuhashi score (Table 1). The patients' general condition was evaluated using Karnofsky's performance status (KPS) at the start of treatment for spinal metastasis, i.e., they were divided into poor (KPS 10-40\%) $(n=22)$, moderate (KPS: $50-$ $70 \%), \quad(n=30)$, and good (KPS 80-100\%) $(n=126)$ groups. The mean survival times of the poor, moderate, and good groups were $2.1 \pm 2.4,5.4 \pm 6.1$, and 11.1 \pm 14.3 months, respectively. There were significant differences between the survival times of the poor and good groups $(p=0.0019)$ and between those of the moderate and good groups $(p=0.0321)$.

In addition, the subjects were divided into three groups based on the number of extraspinal bone metastases that they possessed, i.e., into those with $\geq 3$ ( $n=$ 99), $1-2(n=17)$, and $0(n=40)$ extraspinal bone metastases. The mean survival times of these three groups were $10.3 \pm 14.7,11.1 \pm 15.3$, and $11.0 \pm 19.7$ months, respectively. The difference among them was not significant $(p=0.9604)$.

Furthermore, we examined how the number of spinal metastases influenced the mean survival time. As a result, we found that it was $8.1 \pm 9.4,13.9 \pm 23.4$, and 6.3 \pm 7.3 months in the patients with $\geq 3(n=121), 2(n=$ $29)$, and $1(n=57)$ spinal metastases, respectively. The difference among them was not significant ( $p=0.1388$ ).

As for the effect of the presence/absence of major internal organ metastasis, the mean survival time was 10.5 \pm 16.7 months in the 132 patients with major internal organ metastasis and $11.7 \pm 12.9$ months in the 22 patients without such metastasis $(p=0.6994)$. In addition, the mean survival time was $8.1 \pm 9.3$ months in the patients with liver metastasis $(n=46)$ and $11.7 \pm 12.9$ months in those without it $(p=0.3543)$.

Paralysis was evaluated using Frankel's classification. The mean survival time was $5.2 \pm 3.3$ months in the patients with complete paralysis (Frankel: A, B), 5.5 \pm 7.0 months in those with incomplete paralysis (Frankel C, D), and $11.3 \pm 16.7$ months in those that were free from paralysis (Frankel E). There was a significant difference between the mean survival times of the incomplete paralysis and paralysis-free groups $(p=0.0279)$.

With respect to the total Tokuhashi score, the mean survival time was $9.1 \pm 14.6$ months in the patients with scores of $\leq 8$ points (life expectancy $<6$ months) and $16.7 \pm 16.3$ months in those with scores of 9 to 10 points (life expectancy $\geq 6$ months) ( $p=0.1542$ ).

\section{Laboratory data}

The laboratory data obtained at the start of treatment for spinal metastasis were analyzed. The patients with ALP levels of $<400 \mathrm{IU} / \mathrm{L}(n=85)$ and $\geq 400 \mathrm{IU} / \mathrm{L}(n=$
70) exhibited mean survival times of $13.0 \pm 20.5$ and 8.8 \pm 9.5 months, respectively $(p=0.0961)$. An ALP cut-off level of $400 \mathrm{IU} / \mathrm{l}$ was employed based on the finding that an ALP level of $\geq 400 \mathrm{IU} / \mathrm{l}$ is a potential indicator of high bone metastasis activity [20].

Furthermore, the patients with CEA levels of < $120 \mathrm{ng} / \mathrm{ml}(n=111)$ and $\geq 120 \mathrm{ng} / \mathrm{ml}(n=36)$ displayed mean survival times of $10.2 \pm 14.9$ and $8.9 \pm 1$ months, respectively $(p=0.5189)$. A CEA cut-off level of $120 \mathrm{ng} / \mathrm{ml}$ was employed based on the fact that a CEA level of > $120 \mathrm{ng} / \mathrm{ml}$ was reported to be associated with an increased risk of bone metastasis [2].

\section{Presence/absence of molecule-targeting drug treatment}

Of the various conservative treatments administered to the patients in this study, only molecule-targeting agents and BMA were used as part of a consistent treatment strategy. The other conservative treatments were not used as part of a consistent treatment strategy because their indications or the doctors' approach to treatment changed over time. Therefore, these other conservative treatments could not be evaluated as prognostic factors. The administered molecule-targeting drugs included gefitinib, erlotinib, bevacizumab, axitinib, crizotinib, and afatinib. In 59 patients, these molecule-targeting drugs were used for $\geq 1$ month. In 126 patients, molecule-targeting drug treatment was discontinued within 1 month due to adverse reactions or no such drugs were used.

The former and latter groups exhibited mean survival times of $15.0 \pm 21.1$ and $7.3 \pm 10.4$ months, respectively $(p=0.0093)$.

\section{Presence/absence of bone-modifying agent treatment}

In 143 patients, BMA, such as zoledronic acid or denosumab, were used. In 64 patients, no such drugs were used.

The former and latter groups exhibited mean survival times of $8.2 \pm 15.8$ and $8.6 \pm 10.2$ months, respectively ( $p=$ $0.8650)$.

\section{Multivariate analyses of the factors that influence post- treatment survival}

The results of the univariate analyses are shown in Table 2. In the univariate analyses, the pathology of the primary lung cancer, the patient's general condition and paralysis state, and the presence/absence of moleculetargeting drug treatment were found to significantly influence post-treatment survival. Multivariate analysis was performed using Cox's regression analysis among the 168 patients for whom data on the four abovementioned factors were available.

The patient's general condition and paralysis state were found to have significant effects on survival 
Table 2 Significant differences of survival periods (months)

\begin{tabular}{lc}
\hline Factor & $p$ value \\
\hline Sex. & \\
Male:female & 0.0803 \\
Age (years) $\leq 69$ vs $\geq 70$ & 0.8002 \\
Symptomatic level Cervical vs & 0.1603 \\
thoracic vs lumbosacral & \\
Pathology Adenocarcinoma & $0.0263^{*}$ \\
vs non-adenocarcinoma & \\
Tokuhashi score & \\
General condition & \\
Poor vs good & $0.0019^{*}$ \\
Moderate vs good & $0.0321^{*}$ \\
Number of extraspinal bone metastases foci & 0.9604 \\
Number of metastases in the vertebral body & 0.1388 \\
Metastases to the major internal organs & 0.6994 \\
Paralysis (spinal cord palsy) & $0.0279^{*}$ \\
Total score $\leq 8$ vs 9-10 & 0.1542 \\
ALP 400 IU/L $\geq$ or < & 0.0961 \\
CEA 120 ng/ml $\geq$ or < & 0.5189 \\
Molecular target drug, use (for $\geq 1$ month) or not & $0.0093^{*}$ \\
Bone-modifying agent, use or not & 0.8650 \\
\hline *Significant difference ( $\boldsymbol{2}<0.05$ ). ALP indicates Alkaline phosphatase, CEA \\
\end{tabular}

(Table 3). Based on the hazard ratios for these two factors, we created novel scoring criteria for predicting the prognoses of patients with lung cancer-derived metastatic spine tumors (Table 4, Fig. 1). The maximum total score was 6 points (general condition 4; state of paralysis 2) (Table 4), and total scores of 0 to 2 points, 3 to 5 points, and 6 points indicated a life expectancy of $<6$ months, $<1$ year, and $\geq 1$ year, respectively (Fig. 1). A retrospective review of 168 subjects

Table 3 Multivariate analysis of the prognostic factors affecting survival

\begin{tabular}{llll}
\hline Factor & Hazard ratio & $\begin{array}{l}\text { 95\% confidence } \\
\text { interval }\end{array}$ & $p$ value \\
\hline $\begin{array}{l}\text { Pathology } \\
\text { Adenocarcinoma } \\
\text { or not }\end{array}$ & 0.933 & $0.667-1.306$ & 0.6874 \\
$\begin{array}{l}\text { General condition } \\
\text { (KPS) }\end{array}$ & 0.406 & $0.323-0.510$ & $9.10403 \mathrm{E}-15^{*}$ \\
$\begin{array}{l}\text { 10-40 or 50-70 } \\
\text { or } 80-100\end{array}$ & & & \\
$\begin{array}{l}\text { Paralysis } \\
\text { (Frankel grade) }\end{array}$ & 0.738 & $0.558-0.976$ & $0.0333^{*}$ \\
A, B or C, D or E & & & \\
$\begin{array}{l}\text { Molecular targeted } \\
\text { drug } \\
\text { use or not }\end{array}$ & 0.867 & $0.722-1.041$ & 0.1263 \\
\hline
\end{tabular}

*Mean $p$ value was less than 0.05 , and considered statistically significant KPS indicates Karnofsky's performance status demonstrated consistency rates of $87.5,84.4$, and $47.5 \%$ between the life expectancy predictions obtained using the novel scoring system and survival. The overall consistency rate was $67.3 \%$ (Table 5). In addition, we prepared a second scoring system for predicting the prognoses of patients with lung cancer-derived metastatic spine tumors based on the four factors that exhibited significance in the univariate analyses (Table 4, Fig. 2). The criteria for this scoring system consisted of the patient's general condition (4 points) and paralysis state ( 2 points), the pathology of the primary lung cancer (2 points), and the presence/absence of molecule-targeting drug treatment (2 points). The maximum total score was 10 points, and total scores of 0 to 5 points, 6 to 9 points, and 10 points indicated a life expectancy of $<6$ months, $<1$ year, and $\geq 1$ year, respectively (Table 4, Fig. 2). A retrospective review of 168 subjects demonstrated consistency rates of 82.6, 77.6, and $64.8 \%$ between the life expectancy predictions obtained using the second scoring system and survival. The overall consistency rate was $76.2 \%$ (Table 5).

\section{Discussion}

The prognosis of patients with metastatic spine tumors depends on the type of tumor. The survival times of patients with some types of carcinoma have increased due to advances in treatment, but this is not the case for patients with other types of carcinoma. Lung cancer patients belong to the former group [10]. We previously used a revised version of the Tokuhashi score to predict the prognosis of lung cancer patients [13], but the introduction of molecule-targeting drugs (gefitinib) and BMA from 2002 onwards has markedly improved the prognosis of lung cancer patients. Thus, such patients are surviving for longer than they are predicted to according to the Tokuhashi score. Hessler $\mathrm{C}$ et al. also reported that patients with lung cancer-derived spinal metastasis are surviving longer [21].

On the other hand, recent studies have indicated that the median survival time of patients with spinal metastasis from pulmonary adenocarcinoma was 3.5 or 5.2 months $[5,6]$. In other words, the survival of patients with spinal metastasis from lung cancer varies, and so the importance of predicting patient prognosis when selecting the optimal treatment strategy for lung cancer-derived spinal metastasis has increased.

Goodwin CR et al. indicated that the factors that influence the prognosis of patients with lung cancer-derived spinal metastasis include age, motor function, the presence/absence of major internal organ metastasis, and the presence/absence of extra-thoracic metastasis [6].

Aydinli $\mathrm{U}$ et al. reported that among patients with spinal metastasis, those with squamous cell carcinoma showed the most favorable prognosis followed by adenocarcinoma 
Table 4 A novel scoring system of predicting life expectancy for the patients with metastatic spine tumor from lung cancer

\begin{tabular}{ll}
\hline Predictive factor & Score (points) \\
\hline General condition & 0 \\
Poor (KPS 10-40\%) & 2 \\
Moderate (KPS 50-70\%) & 4 \\
Good (KPS 80-100\%) & \\
Paralysis & 0 \\
Complete (Frankel A, B) & 1 \\
Incomplete (Frankel C, D) & 2 \\
None (Frankel E) & \\
Pathology & 0 \\
Non-adenocarcinoma & 2 \\
Adenocarcinoma & \\
Molecular target drug & \\
No use & \\
Use &
\end{tabular}

6 points predictive score: general condition + paralysis

10 points predictive score: general condition + paralysis + pathology + molecular target drug

KPS indicates Karnofsky's performance status

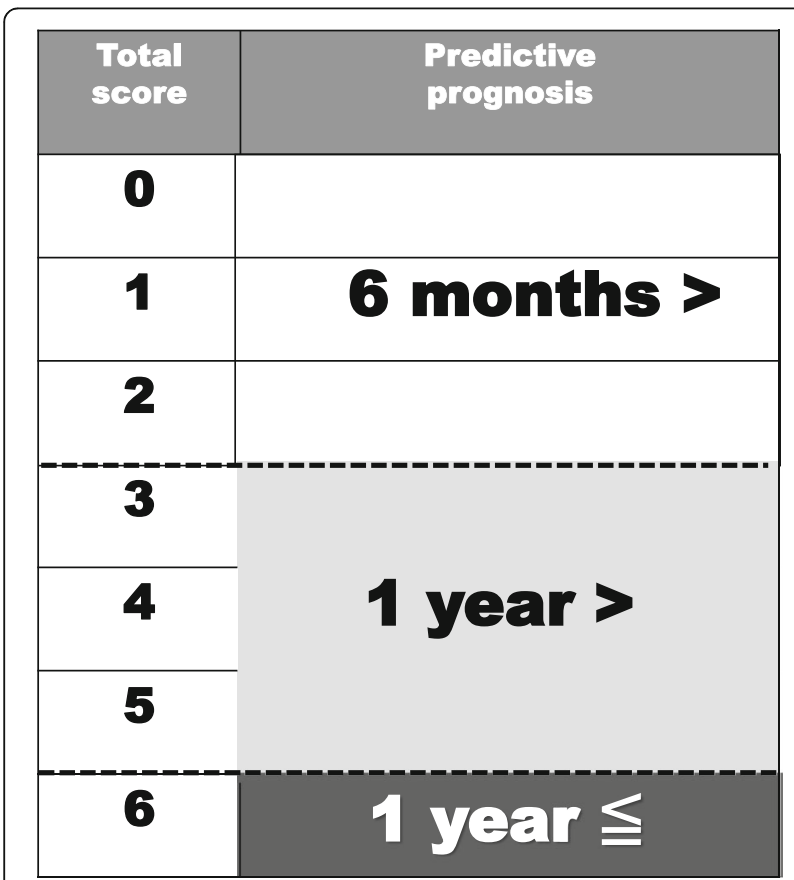

Fig. 1 Criteria for predicting the prognosis of patients with lung cancer-derived metastatic spine tumors (maximum total score 6 points). Total scores of 0 to 2 points, 3 to 5 points, and 6 points were indicative of a life expectancy of $<6$ months, $<1$ year, and $\geq 1$ year, respectively and small cell carcinoma patients [3]. It is unclear why the adenocarcinoma group exhibited a significantly better prognosis than the non-adenocarcinoma group in our series. Since adenocarcinoma accounted for more than two-thirds of our cases, the subjects were divided into two pathology groups, the adenocarcinoma and nonadenocarcinoma groups. Generally, lung cancer patients with squamous cell carcinoma have a better prognosis than those with adenocarcinoma, and it has been suggested that lung cancer patients with small cell carcinoma have a worse prognosis than those with adenocarcinoma. In the present study, the non-adenocarcinoma group only included a few cases of squamous cancer, whereas it included relatively many cases of small cell cancer. We consider that this might explain why the mean survival time of the adenocarcinoma group was longer than that of the non-adenocarcinoma group. In addition, the fact that molecule-targeting drugs could be administered to the adenocarcinoma group based on genetic screening might have contributed to the marked prognostic improvement associated with the use of molecule-targeting drugs.

Lei $\mathrm{M}$ et al. reported that the patient's preoperative gait, the presence/absence of major internal organ metastasis, and the interval from onset until motor paralysis influenced the prognosis of lung cancer patients with spinal metastasis [22]. In univariate analyses, Park SJ et al. found that the prognostic factors for spinal metastasis derived from non-small cell cancer included the time since the appearance of neurological findings, the response to preoperative chemotherapy, postoperative chemotherapy, performance status, and postoperative gait [5]. The subsequent multivariate analysis demonstrated that the time since the appearance of neurological findings, postoperative chemotherapy, and performance status were significant prognostic factors. According to Sugiura $\mathrm{H}$, being female, a favorable performance status, adenocarcinoma, gefitinib (a molecule-targeting drug) treatment, having a solitary lesion, and the absence of long bone metastasis contributed to a favorable prognosis in lung cancer patients with bone metastasis [23]. Katagiri et al. [11] also reported that molecule-targeting drug treatment influences the prognosis of patients with bone metastasis and reported a scoring system involving these drugs for predicting the prognosis of such patients.

Furthermore, a previous study indicated that ALP and CEA [2] measurements are useful for the auxiliary diagnosis of bone metastasis. However, in our series, these factors did not have a significant influence on survival. The serum level of bone-specific ALP has been reported to be useful for predicting the prognosis of patients with bone metastasis or renal cancer [24, 25], but the level of this ALP isozyme was not assessed in the current study. Therefore, an increased ALP level is not 
Table 56 and 10 points predictive score vs survival periods (months)

\begin{tabular}{|c|c|c|c|c|c|c|}
\hline & & \multicolumn{5}{|c|}{ Survival periods } \\
\hline \multirow{8}{*}{$\begin{array}{l}6 \text { points } \\
\text { predictive } \\
\text { score }\end{array}$} & Score & 6 months> & $6-12$ months & 12 months < & Total & Mean \pm SD \\
\hline & 0 & 0 & 0 & 0 & 0 & \\
\hline & 1 & 3 & 0 & 0 & 3 & $1.50 \pm 0.87$ \\
\hline & 2 & 18 & 3 & 0 & 21 & $2.30 \pm 3.05$ \\
\hline & 3 & 4 & 1 & 3 & 8 & $8.84 \pm 9.41$ \\
\hline & 4 & 14 & 4 & 1 & 19 & $6.29 \pm 10.6$ \\
\hline & 5 & 26 & 5 & 6 & 37 & $6.21 \pm 7.27$ \\
\hline & 6 & 26 & 16 & 38 & 80 & $15.6 \pm 20.0$ \\
\hline Total & & 91 & 29 & 48 & 168 & \\
\hline 10 points & 0 & 0 & 0 & 0 & 0 & \\
\hline predictive score & 1 & 1 & 0 & 0 & 1 & 2.5 \\
\hline & 2 & 6 & 1 & 0 & 7 & $2.50 \pm 3.85$ \\
\hline & 3 & 4 & 0 & 1 & 5 & $5.30 \pm 7.71$ \\
\hline & 4 & 12 & 2 & 1 & 15 & $5.84 \pm 12.0$ \\
\hline & 5 & 15 & 2 & 1 & 18 & $4.41 \pm 5.78$ \\
\hline & 6 & 17 & 5 & 7 & 29 & $9.28 \pm 12.4$ \\
\hline & 7 & 9 & 5 & 4 & 18 & $8.51 \pm 9.31$ \\
\hline & 8 & 16 & 10 & 6 & 32 & $8.69 \pm 11.6$ \\
\hline & 9 & 4 & 0 & 2 & 6 & $7.13 \pm 6.24$ \\
\hline & 10 & 7 & 6 & 24 & 37 & $20.6 \pm 24.9$ \\
\hline Total & & 91 & 31 & 46 & 168 & \\
\hline
\end{tabular}

a specific finding of spinal metastasis derived from lung cancer because elevated ALP levels are seen in other diseases. Future studies should examine whether the serum level of bone-specific ALP is a prognostic factor for patients with spinal metastasis from lung cancer.

Finally, a recent study investigated the size of the psoas muscle as a prognostic factor in lung cancer patients with spinal metastasis [26].

Despite the abovementioned findings, it should be noted that none of the examined factors have been definitively proven to influence the prognosis of patients with lung cancer-derived spinal metastasis. In addition, our scoring system was created based on the results of a retrospective study. Thus, an additional study of our 10-point scoring system should be conducted.

As for the limitations of this study, it was a retrospective study (rather than a prospective randomized study). In addition, the subjects were restricted to symptomatic patients with metastatic spine tumors. Regarding laboratory data, the serum level of bone-specific ALP should be evaluated as a prognostic factor in future.

Furthermore, our study included a factor relating to the therapeutic intervention, i.e., the presence/absence of molecule-targeting drug treatment. Unexpected factors, such as treatment discontinuation due to adverse reactions, were also included; however, not all patients were indicated for fixed treatments. Except for molecule-targeting drug or BMA treatment, none of the conservative treatments could be evaluated as prognostic factors. This is also a limitation of the current study, and a further evaluation is necessary once a clear treatment strategy for lung cancer-derived metastatic spine tumors has been established.

According to the standard approach, our prognostic scoring system should only have included the two factors that displayed significance in the multivariate analysis, i.e., the patient's general condition and paralysis state. However, a retrospective review showed that a scoring system involving a combination of the four factors that exhibited significance in the univariate analyses, i.e., the patient's general condition and paralysis state, the pathology of the primary lung cancer, and the presence/absence of molecule-targeting drug treatment, was more accurate. However, the efficacy of our 2- and 4-factor scoring systems must be reviewed in a larger number of patients in the future.

\section{Conclusions}

The results of the univariate analyses demonstrated that the patient's general condition and paralysis state, the pathology of the primary lung tumor, and molecule-targeting drug treatment influenced survival among patients 


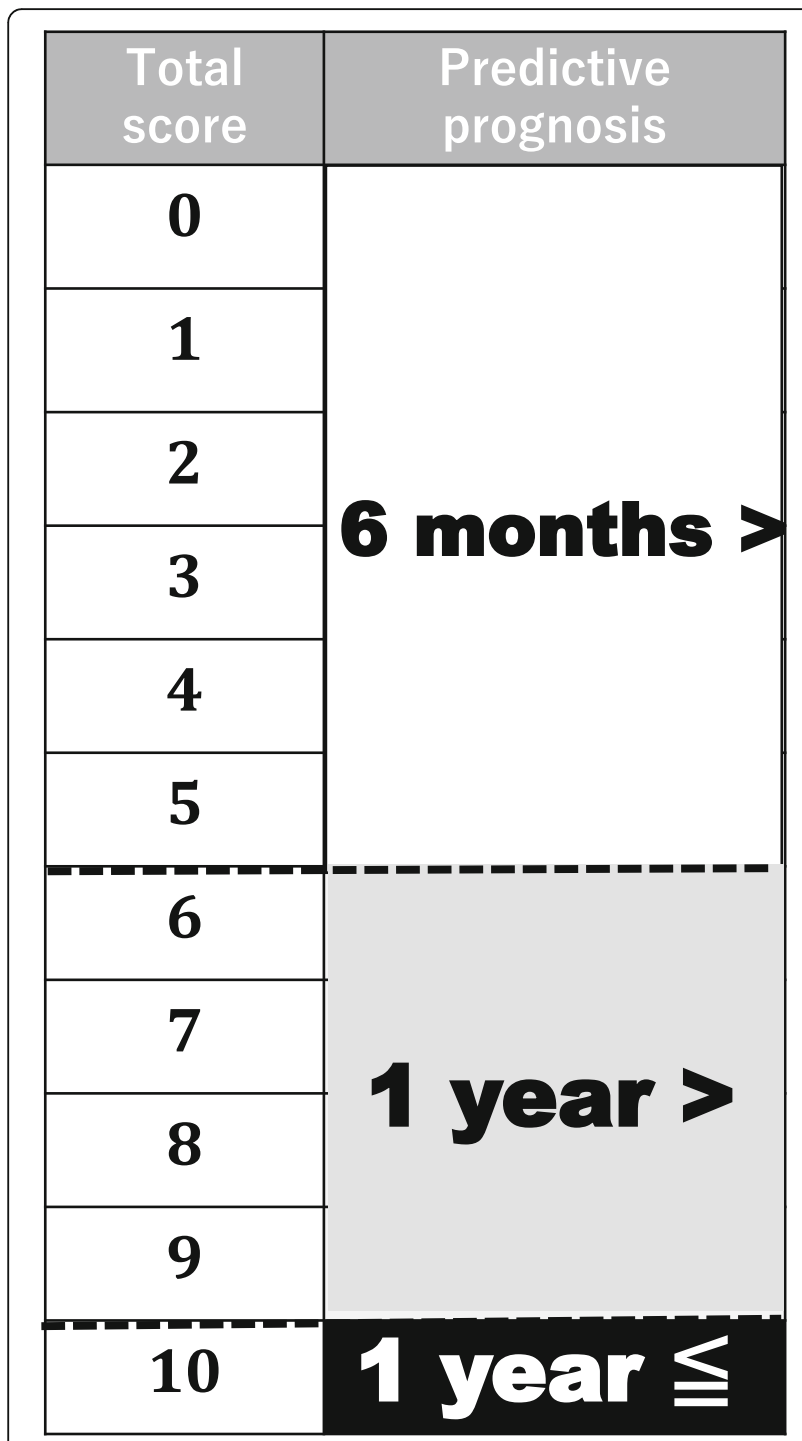

Fig. 2 Criteria for predicting the prognosis of patients with lung cancer-derived metastatic spine tumors (maximum total score 10 points). Total scores of 0 to 5 points, 6 to 9 points, and 10 points were indicative of a life expectancy of $<6$ months, $<1$ year, and $\geq 1$ year, respectively

with lung cancer-derived metastatic spine tumors. The novel scoring systems based on these four factors was more accurate than that based on the two factors that exhibited significance in the multivariate analysis. These simple scoring systems are useful for aiding the selection of appropriate treatment modalities for progressive spinal metastasis. Additional clinical studies with larger sample sizes are required to further validate these findings.

\section{Availability of data and materials}

The datasets obtained in this study are available from the corresponding author on reasonable request.

\section{Authors' contributions}

HU designed this study, YT collected the data, HU and YT analyzed the data, $\mathrm{HU}$ edited the paper, and $\mathrm{YT}$ approved the final version of the manuscript. Both authors read and approved the final manuscript.

Ethics approval and consent to participate

All procedures performed in studies involving human participants were conducted in accordance with the ethical standards of the institutional and/ or national research committee and with the 1964 Helsinki declaration and its later amendments or comparable ethical standards. Institutional review board approval was obtained from Nihon University Itabashi Hospital (approval number RK-11209-8).

Consent for publication

Not applicable

\section{Competing interests}

The authors declare that they have no competing interests.

\section{Publisher's Note}

Springer Nature remains neutral with regard to jurisdictional claims in published maps and institutional affiliations.

Received: 29 January 2018 Accepted: 29 June 2018

Published online: 05 July 2018

\section{References}

1. TIsuya A, Kurata T, Tamura K, Fukuoka M. Skeletal metastases in non-small cell lung cancer: a retrospective study. Lung Cancer. 2007;57:229-32.

2. Ryo H, Sakai H, Yoneda S, Noguchi Y. Bone metastasis of primary lung cancer. Nihon Kokyuki Gakkai Zasshi. 1998;36:317-22.

3. Aydinli U, Ozturk C, Bayram S, Sarihan S, Evrensel T, Yilmaz HS. Evaluation of lung cancer metastases to the spine. Acta Orthop Belg. 2006;72:592-7.

4. Aydin AL, Emel E, Sasani M, Gomleksiz C, Oktenoglu T, Ozer AF. Lung cancer metastasis to the spine. Turk Neurosurg. 2016;26:635-42.

5. Park SJ, Lee CS, Chung SS. Surgical results of metastatic spinal cord compression (MSCC) from non-small cell lung cancer (NSCLC): analysis of functional outcome, survival time, and complication. Spine J. 2016;16:322-8.

6. Goodwin CR, Khattab MH, Sankey EW, Elder BD, Kosztowski TA, SarabiaEstrada R, Bydon A, Witham TF, Wolinsky JP, Gokaslan ZL, Sciubba DM. Factors associated with life expectancy in patients with metastatic spine disease from adenocarcinoma of the lung. Global Spine J. 2015:5:417-24.

7. Carr LL, Finigan JH, Kern JA. Evaluation and treatment of patients with nonsmall cell lung cancer. Med Clin North Am. 2011;95:1041-54.

8. Gregory TM, Coriat R, Mir O. Prognostic scoring systems for spinal metastases in the era of anti-VEGF therapies. Spine (Phila Pa 1976). 2013;38: 965-6.

9. Cagle PT, Chirieac LR. Advances in treatment of lung cancer with targeted therapy. Arch Pathol Lab Med. 2012;136:504-9.

10. Morgen SS, Lund-Andersen C, Larsen CF, Engelholm SA, Dahl B. Prognosis in patients with symptomatic metastatic spinal cord compression: survival in different cancer diagnosis in a cohort of 2321 patients. Spine (Phila Pa 1976). 2013;38:1362-7.

11. Katagiri H, Okada R, Takagi T, Takahashi M, Murata H, Harada H, Nishimura T, Asakura $\mathrm{H}$, Ogawa $\mathrm{H}$. New prognostic factors and scoring system for patients with skeletal metastasis. Cancer Med. 2014;3:1359-67.

12. Tokuhashi Y, Matsuzaki H, Toriyama S, Kawano H, Ohsaka S. Scoring system for the preoperative evaluation of metastatic spine tumor prognosis. Spine (Phila Pa 1976). 1990;15:1110-3.

13. Tokuhashi Y, Matsuzaki H, Oda H, Oshima M, Ryu J. A revised scoring system for preoperative evaluation of metastatic spine tumor prognosis. Spine (Phila Pa 1976). 2005;30:2186-91.

14. Enkaoua EA, Doursounian L, Chatellier G, Mabesoone F, Aimard T, Saillant G. Vertebral metastases: a critical appreciation of the preoperative prognostic Tokuhashi score in a series of 71 cases. Spine (Phila Pa 1976). 1997:22:2293-8.

15. Aoude A, Amiot LP. A comparison of the modified Tokuhashi and Tomita scores in determining prognosis for patients afflicted with spinal metastasis. Can J Surg. 2014;57:188-93. 
16. Yamashita T, Siemionow KB, Mroz TE, Podichetty V, Lieberman IH. A prospective analysis of prognostic factors in patients with spinal metastases: use of the revised Tokuhashi score. Spine (Phila Pa 1976). 2011;36:910-7.

17. Eap C, Tardieux E, Goasgen O, Bennis S, Mireau E, Delalande B, Cvitkovik F, Baussart B, Aldea S, Jovenin N, Gaillard S. Tokuhashi score and other prognostic factors in 260 patients with surgery for vertebral metastases. Orthop Traumatol Surg Res. 2015;101:483-8.

18. Zoccali C, Skoch J, Walter CM, Torabi M, Borgstrom M, Baaj AA. The Tokuhashi score: effectiveness and pitfalls. Eur Spine J. 2016;25:673-8.

19. Wang $M$, Bunger $C E$, Li H, Wu C, Hoy K, Niedermann B, Helmig P, Wang $Y$, Jensen AB, Schattiger K, Hansen ES. Predictive value of Tokuhashi scoring systems in spinal metastases, focusing on various primary tumor groups: evaluation of 448 patients in the Aarhus spinal metastases database. Spine (Phila Pa 1976). 2012;37:573-82.

20. Koyanagi H, Shimoji T, Kawabata A, Nagumo Y, Ishikawa F, Okawa A, Manabe A. Serum alkaline phosphatase as a biomarker for clinical feature of bone metastases patients with carcinomas. J Jpn Orthop Assoc. 2016;90: S1251.

21. Hessler C, Vettorazzi E, Madert J, Bokemeyer C, Panse J. Actual and predicted survival time of patients with spinal metastases of lung cancer: evaluation of the robustness of the Tokuhashi score. Spine (Phila Pa 1976). 2011:36:983-9

22. Lei M, Liu Y, Yan L, Tang C, Yang S, Liu S. A validated preoperative score predicting survival and functional outcome in lung cancer patients operated with posterior decompression and stabilization for metastatic spinal cord compression. Eur Spine J. 2016;25:3971-8.

23. Sugiura H. Encounter of cancer cells with bone. Therapy for bone metastasis from lung cancer. Clin Calcium. 2011;21:439-45.

24. Du WX, Duan SF, Chen JJ, Huang JF, Yin LM, Tong PJ. Serum bone-specific alkaline phosphatase as a biomarker for osseous metastases in patients with malignant carcinomas: a systematic review and meta-analysis. J Cancer Res Ther. 2014;10(Suppl):C140-3.

25. Prasad R, Lambe S, Kaler P, Pathania S, Kumar S, Attri S, Singh SK. Ectopic expression of alkaline phosphatase in proximal tubular brush border membrane of human renal cell carcinoma. Biochim Biophys Acta. 2005; 1741:240-5

26. Zakaria HM, Basheer A, Boyce-Fappiano D, Elibe E, Schultz L, Lee I, Siddiqui F, Griffith B, Chang V. Application of morphometric analysis to patients with lung cancer metastasis to the spine: a clinical study. Neurosurg Focus. 2016; 41:E12.

Ready to submit your research? Choose BMC and benefit from:

- fast, convenient online submission

- thorough peer review by experienced researchers in your field

- rapid publication on acceptance

- support for research data, including large and complex data types

- gold Open Access which fosters wider collaboration and increased citations

- maximum visibility for your research: over $100 \mathrm{M}$ website views per year

At BMC, research is always in progress.

Learn more biomedcentral.com/submissions 